\title{
ОРГАНИЗАЦИОННЫЙ МЕХАНИЗМ УПРАВЛЕНИЯ ИНТЕГРАЦИОННЫМИ ПРОЦЕССАМИ В ОБРАЗОВАНИИ
}

\section{ORGANIZATIONAL MECHANISM FOR MANAGING INTEGRATION PROCESSES IN EDUCATION}

\section{N. Galchenko}

Summary: The article examines the organizational structure of education management as a set of forms and relationships of the organizational structure of education management subsystems, which should act in accordance with the functional goals of education integration. The author describes the stages of the formation of the education system in the regions. Particular attention is paid to the unifying trends in education management. This is carried out in the course of the emergence and resolution of contradictions caused by the complex interaction of integration and differentiation in educational activities.

Keywords: integrative processes, institutionalization of management, organizational structure, education, differentiation, model.

\author{
Гальченко Наталья Александровна \\ Дочент, Мурманский арктический \\ государственный университет \\ galchenko.n.a@mail.ru
}

Аннотация: В статье рассматривается организационная структура управления образованием как совокупность форм и взаимосвязей организационного построения подсистемы управления образованием, которые должны действовать согласно функциональным целям интеграции образования. Автор характеризует этапы формирования системы образования в регионах. Особое внимание уделяется объединяющей тенденции в управлении образованием. Она осуществляется в ходе возникновения и разрешения противоречий, обусловленных сложным взаимодействием интеграции и дифференциации в образовательной деятельности.

Ключевые слова: интегративные процессы, институционализация управления, организационная структура, образование, дифференциация, модель.
Организационную структуру управления интеграционными процессами в образовании необходимо рассматривать как совокупность форм и взаимосвязей организационного построения подсистемы управления образованием. Эти формы и взаимосвязи на региональном уровне в принципе должны действовать адекватно функциональным целям интеграции образования.

По нашему мнению, процесс институционализации управления интеграцией института образования в регионе находится на различных стадиях в зависимости от конкретных условий субъектов Российской Федерации. Необходимо четко диагностировать эту стадию, чтобы, во-первых, правильно определить необходимые в данный конкретный момент организационно-технологические решения; во-вторых, прогнозировать последовательность проектной деятельности в сфере образования.

Представляется возможным предложить следующий алгоритм оценки процесса институционализации управления интеграционным развитием в образовании и в зависимости от нее - определения приоритетов организационной работы (см. таблица 1)

Предложенный алгоритм дает, на наш взгляд, возможность проанализировать состояние управления интеграционными процессами в условиях конкретного субъекта Российской Федерации. Применение ее к ана- лизу интеграционных процессов в некоторых регионах России, которые послужили основным объектом эмпирических исследований, позволяет нам определить разрешение проблемы институционализации в них управлением интеграцией в образовании. В соответствии с предложенным алгоритмом можно утверждать, что более всего в данном направлении продвинулась Воронежская область, в которой реализуются закон об образовании и программа развития образования и информатизации образования на 2014 - 2020 гг., создан региональный университетский учебный округ.

В регионе осуществляется распоряжение главы администрации «О мерах по формированию областного заказа на подготовку кадров в системе профессионального образования области». Область, по нашему мнению, находится на третьем этапе институционализации управления интеграционными процессами.

На втором этапе процесса институционализации находятся три остальных региона. В них не решены некоторые проблемы институционализации управления, специфические для каждого субъекта РФ. В Белгородской области, несмотря на то что управление образованием сконцентрировано в одной структуре и принята программа развития образования, идея формирования регионального учебного округа находится в стадии обсуждения. 
Таблица 1.

Алгоритм оценки процесса институционализации управления интеграцией образования в регионе

\begin{tabular}{|c|c|c|}
\hline Этап становления системы & Показатели & $\begin{array}{l}\text { Приоритетные направления деятельности органов } \\
\text { управления }\end{array}$ \\
\hline Этап формирования & $\begin{array}{l}\text { Децентрализация управления образованием. } \\
\text { Регламентация функционирования образовательного } \\
\text { пространства в общих нормативных актах (Консти- } \\
\text { туция; Устав; законы, регулирующие иные виды дея- } \\
\text { тельности). } \\
\text { Отсутствие концепции развития образования. } \\
\text { Фрагментарное информационное пространство об- } \\
\text { разования (информационные системы отдельных } \\
\text { учреждений) Связи между отдельными образова- } \\
\text { тельными учреждениями и другими социальными } \\
\text { институтами. } \\
\text { Отсутствует система подготовки и переподготовки ка- } \\
\text { дров управления образованием. }\end{array}$ & $\begin{array}{l}\text { Формирование единого органа управления образова- } \\
\text { нием в регионе. } \\
\text { Разработка закона об образовании и концепции раз- } \\
\text { вития образования. Формирование горизонтальных } \\
\text { интегрированных структур управления образованием } \\
\text { (советы директоров образовательных учреждений; } \\
\text { советы ректоров). Развитие единых информационных } \\
\text { систем между образовательными учреждениями од- } \\
\text { ного уровня. } \\
\text { Внедрение единых региональных заказов для образо- } \\
\text { вательных учреждений одного уровня. } \\
\text { Разработка региональной программы подготовки } \\
\text { управленческих кадров для образования. } \\
\text { Разработка нормативной базы для формирования } \\
\text { университетских комплексов. }\end{array}$ \\
\hline Эman становления & $\begin{array}{l}\text { Создание единого органа управления образованием в } \\
\text { регионе. } \\
\text { Принятие закона об образовании. Разработка концеп- } \\
\text { ции развития образования. } \\
\text { Наличие горизонтальных структур управления об- } \\
\text { разованием (советы директоров образовательных } \\
\text { учреждений, советы ректоров) Интеграция информа- } \\
\text { ционных систем образовательных учреждений одного } \\
\text { уровня. } \\
\text { Действует система единых региональных заказов для } \\
\text { образовательных учреждений одного уровня. } \\
\text { Разработана региональная программа подготовки } \\
\text { управленческих кадров для образования. } \\
\text { Начато формирование университетских комплексов. }\end{array}$ & 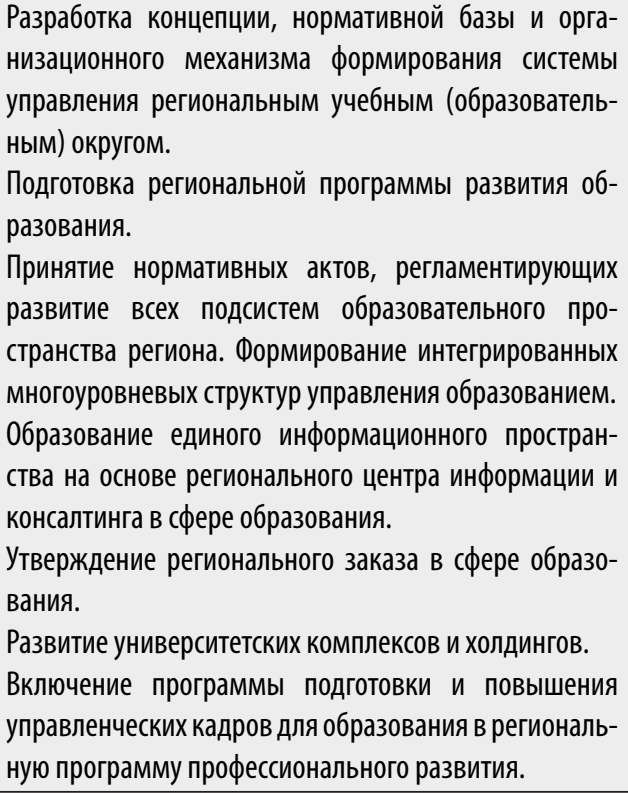 \\
\hline Этап функционирования & $\begin{array}{l}\text { Сформирована система управления региональным } \\
\text { учебным (образовательным) округом. } \\
\text { Реализуются региональная концепция и программа } \\
\text { развития образования. Действует система норматив- } \\
\text { ных актов, регламентирующих развитие образова- } \\
\text { тельного пространства региона. } \\
\text { Созданы интегрированные многоуровневые структу- } \\
\text { ры управления образованием. } \\
\text { Сформировано единое информационное простран- } \\
\text { ство. } \\
\text { Оформлен общий региональный заказ в сфере обра- } \\
\text { зования. } \\
\text { Развиваются университетские комплексы и холдинги. } \\
\text { Программа подготовки и повышения управленческих } \\
\text { кадров для образования включена в региональную } \\
\text { программу профессионального образования. }\end{array}$ & $\begin{array}{l}\text { Разработка долгосрочного прогноза развития образо- } \\
\text { вания в регионе. } \\
\text { Внедрение единой системы управления качеством на } \\
\text { уровне субъекта Российской Федерации. } \\
\text { Развитие межрегиональных интеграционных связей, } \\
\text { создание условий для интеграции в региональную об- } \\
\text { разовательную систему несистемных элементов. Раз- } \\
\text { витие межуниверсистетских учебнонаучных проектов } \\
\text { и связей. } \\
\text { Включение институтов гражданского общества в про- } \\
\text { цесс управления региональным образованием, созда- } \\
\text { ние системы социального контроля за образователь- } \\
\text { ной деятельностью. }\end{array}$ \\
\hline
\end{tabular}


В Ростовской области концепция и программа развития образования в регионе находится в стадии разработки. Учебные комплексы создаются на базе отдельных ВУЗов. Но в области осуществляется целевая подготовка специалистов [3,61].

Для Волгоградской области характерно то, что регион наиболее приближен к третьему этапу институционализации. В области эффективно действуют единый орган управления образованием, система нормативных актов, регламентирующих развитие образовательной системы региона, реализуется программа подготовки и повышения квалификации педагогических и управленческих кадров, начинают формироваться университетские комплексы, интегрируются структуры управления образованием.

Анализ состояния процесса институционализации интеграционного развития важен потому, что он позволяет определить стратегию решения проблемы институционализации. При всем разнообразии конкретных задач эта стратегия связана с обоснованием и практической реализацией трех комплексных социально-технологических решений.

\section{1. Формирование правовой основы функционирования еАиной подсистемы управления образованием.}

Многие нормативно-правовые акты субъектов РФ в области образования обычно носят слишком общий, в большей степени организационный характер, требуют разработки и принятия отдельных документов, содержащих механизмы заложенных в них положений.

Эффективность управления образованием, по нашему мнению, может быть высокой, во-первых, при условии правового соответствия регионального законодательства в сфере образования федеральным нормам; во-вторых, в случае, если нормативно-правовые акты субъектов Российской Федерации предоставляют максимально благоприятные условия для функционирования муниципальных образовательных округов, образовательных учреждений и интегрированных структур. Не отрицая принципа приоритетности федерального законодательства в сфере образования по отношению к законодательству на региональном уровне, мы полагаем, что второе играет исключительно важную роль в правовом регулировании интеграционных процессов в образовании и сегодня является ключевым звеном в решении задачи управления ими $[7,43]$.

\section{2. Организашионное оформление подсистемы управления интеграшией образования.}

Данная подсистема включает в себя законодательные органы власти в регионе; исполнительные органы власти; структуры управления образованием в составе исполнительных органов; институты гражданского общества, участвующие в формировании политики в сфере образования; органы управления образованием, возникшие как следствие интеграции его уровней, форм и видов; муниципальные органы управления.

В основу формирования организационной структуры управления образованием, по нашему мнению, должен быть положен структурно-функциональный подход. При этом необходимо учитывать несколько обстоятельств.

Во-первых, подсистема управления образованием в регионе имеет и в перспективе будет иметь три уровня.

Первый- органы законодательной власти и неспециализированные структуры исполнительной власти (например, администрации и правительства в целом), компетенция которых предельно широка в решении общих вопросов, но в то же время должна быть ограничена в отношении частных проблем, предполагающих либо ведомственную, либо функционально-целевую специализацию.

Функции структур первого уровня определяются их конституционно-правовым статусом и обычно структурируются следующим образом. Органы законодательной власти региона утверждают бюджет образования; нормативы финансирования; региональные программы развития образования; устанавливают дополнительные в дополнении к федеральным льготы, виды и нормы материального обеспечения обучающихся, воспитанников, педагогических работников образовательных учреждений; учреждают различные формы поощрений и наград для системы образования.

Органы исполнительной власти исполняют законодательство об образовании; определяют порядок учреждения, открытие и ликвидации образовательных учреждений; организуют финансирование местных органов управления образования и подведомственных образовательных учреждений, оказание им посреднических услуг в части материально-технического обеспечения; формируют государственный орган управления образования и руководят им; устанавливают национально-региональные компоненты государственных образовательных стандартов.

Второй уровень включает в себя государственный орган, непосредственно осуществляющий управление региональной системой образования. Чаще всего это управление, департамент или комитет в составе исполнительной власти. Сегодня он представляет ключевое звено оперативного управления с исключительно широкими полномочиями. В их число обычно входят: контроль исполнения законодательства в сфере образования и реализации прав обучающихся; осуществле- 
ние межведомственной координации деятельности по вопросам образования; взаимодействие с федеральными, муниципальными и негосударственными образовательными учреждениями; разработка и реализация областных целевых программ развития образования; координация деятельности с муниципальными органами управления образования по вопросам реализации государственной политики в сфере образования, региональных и муниципальных программ развития образования; контроль соблюдения государственных образовательных стандартов, установленных правил, нормативов в образовательных учреждениях независимо от форм собственности, в пределах прав, предоставленных законом; инспектирование муниципальных органов управления образованием и образовательных учреждений по вопросам соблюдения законодательства Российской Федерации и региона; разработка национально-регионального компонента государственных образовательных стандартов; организация подготовки, переподготовки и повышения квалификации работников образования; прогнозирование развития сети образовательных учреждений, подготовка предложений по выделению из областного бюджета средств местным бюджетам; осуществление лицензирования образовательных учреждений; приостановление действия или аннулирование лицензии образовательного учреждения в порядке и случаях, предусмотренных федеральным законодательством; передача органам местного самоуправления полномочий по лицензированию и аттестации дошкольных и общеобразовательных учреждений; создание аттестационных и экспертно-диагностических служб в целях разработки и реализации научно-методических основ аттестации выпускников, педагогов и образовательных учреждений; разработка региональных требований к условиям, организации и содержанию образовательной деятельности учреждений различных видов; осуществление государственной аккредитации образовательных учреждений, отнесенных федеральным законодательством к компетенции органа управления образованием субъекта Российской Федерации; содействие проведению научных исследований в сфере образования; развитие информационной инфраструктуры системы образования; научно-методическое и информационное обеспечение образовательных учреждений, организация издания учебной литературы, разработка примерных учебных планов; поддержка инновационной деятельности в образовании; проведение аттестации педагогов и руководителей образовательных учреждений; стимулирование педагогического творчества, качества педагогического труда; формирование регионального заказа на подготовку специалистов в учреждениях начального, среднего и высшего профессионального образования; привлечение общественности к решению проблем образования; обеспечение межрегионального и международного сотрудничества в сфере образования $[4,125]$.
Третий уровень - уровень муниципальных образований. Их компетенции обычно подлежат создание условий для реализации государственной политики в сфере образования; участие в формировании и реализации регионального заказа на подготовку специалистов с начальным, средним и высшим профессиональным образованием; осуществление отбора абитуриентов для целевого приёма в учреждения высшего профессионального образования и контроль за обучением и социальной поддержкой студентов, их трудоустройством; поддержка негосударственных образовательных организаций, находящихся на данной территории; финансирование негосударственных образовательных организаций, реализующих программы дошкольного, основного и среднего (полного) общего образования и имеющих государственную аккредитацию, на основе нормативов минимальной бюджетной обеспеченности; разработка и реализация муниципальных программ развития образования.

По нашему мнению, решающее значение для институционализации управления интеграционными процессами имеет организационное оформление государственного органа, регулирующего данный процесс. Анализ показывает, что в настоящее время эта задача в целом решается на региональном уровне путем создания в органах власти субъектов Российской Федерации единых (интегрированных) структур управления образованием. Однако при этом сохраняется ряд нерешенных проблем.

Во-первых, существует тенденция понижения статуса органа управления образования. Например, в случаях, когда ключевой структурой исполнительных органов власти являются департаменты, органы управления образования включаются в их состав. В частности, в Белгородской области управление образования функционирует в составе департамента социальной политики. Объединение такого рода, с одной стороны, способствует укреплению связей между институтом образования и другими социальными институтами. С другой стороны, понижение статуса структуры сокращает ее потенциал как в отношении стратегического, так и оперативного управления.

Во-вторых, типичной является функциональная неопределенность органов управления образования. Она проявляется в нескольких отношениях. Набор функциональных задач управленческих структур чрезвычайно разнообразен, но, как правило, не соотнесен с их ресурсными возможностями. По меньшей мере, отсутствуют теоретические разработки, обосновывающие выделение конкретных функций. Не случайно в положениях об органах управления образования различных субъектов Российской Федерации существуют серьезные расхождения в определении их функциональных задач. Государственный орган управления образования обычно структурируется с учетом уровней образовательных 
учреждений.

В Мурманской области структура комитета образования следующая: отдел общего образования; отдел дошкольного образования; сектор планирования и экономического развития; отдел воспитания, дополнительного образования и охраны прав несовершенно летних; отдел опеки и попечительства; отдел содержания и текущего ремонта образовательных учреждений; отдел кадровой работы и ведомственного контроля [7].

В Пензенской области - отделы дошкольного образования и воспитания, внешкольного дополнительного образования, развития общего среднего образования, детских домов и школ-интернатов [6].

В Белгородской области управление образования включает в себя: отдел начального профессионального образования; отдел развития среднего профессионального образования; кадровый отдел; планово-бюджетный отдел; отдел науки, высших и средних учебных заведений [8].

В Волгоградской области комитет по управлению образованием представлен управлением социального развития и материально-технического обеспечения. Кроме того, в комитет входят отделы общего образования; дополнительного образования и воспитательной работы; инспектирования; среднего профессионального и высшего профессионального образования; лицензирования и аккредитации; социальной сферы; правового и кадрового обеспечения.

По нашему мнению, решение данной проблемы связано с осуществлением структурной модификации органов управления образования в регионах, которая должна быть проведена с учетом функций данного института в региональном развитии и при условии обеспечения участия в процессе управления всех субъектов образовательного пространства. В результате организационная модель государственного органа управления может выглядеть следующим образом (см. схему 1); представленные в схеме управления отделы реализуют конкретные функциональные цели, соответствующие функциям региональной системы образования. И называться он должен не иначе, как департамент образования, а не министерство, как в некоторых областях.

Аналитический отдел занимается исследованием и оценкой развития общих тенденций, определяющих место системы образования в регионе и ее задачи в контексте стратегии устойчивого развития.

Отдел развития образования разрабатывает проекты и программы развития самой системы образования.

Организационно-контрольное управление занимает- ся оперативным руководством структурами образования всех уровней, решает вопросы подготовки, переподготовки и повышения квалификации кадров. В рамках управления могут быть сформированы самостоятельные отделы, соот-ветствующие уровням образования.

Отдел воспитательных программ занимается управлением воспита-тельной деятельностью в системе образования.

Информационно-социологический отдел осуществляет мониторинг образовательного пространства и формирование имиджа системы образования в целом и ее отдельных структурных элементов.

Возможно объединение данного отдела с аналитическим отделом в рамках единого управления.

Отдел организационно-педагогической работы решает методические проблемы развития системы образования, обеспечивает качество педагогической деятельности на региональном уровне.

Управление разработки и реализации интеграционных проектов обеспечивает взаимодействие элементов системы образования, осуществляет работу по формированию регионального образовательного округа, координирует практическое взаимодействие образования и других социальных институтов.

Отделы целевых программ, ресурсного обеспечения и государственных закупок, бюджетного процесса и экономического анализа, бюджетного учета и финансового контроля занимается ресурсным обеспечением развития системы образования.

Главным достоинством предложенной организационной структуры является ее функциональная ориентированность. При этом к минимуму сводится возможность дублирования функций, а также решения органами управления несвойственных им задач. Кроме того, наличие в структуре департамента образования специального управления разработки и реализации интеграционных проектов выступает в качестве условия эффективного взаимодействия как между элементами системы образования, так и между ею и другими социальными институтами. Тем самым потенциально существующая система образования способна превратиться в актуальную систему, что, на наш взгляд, является важнейшим условием ее эффективности.

Разумеется, предложенная структурная модель управления дает лишь общее представление об органе государственного управления образованием в субъекте Российской Федерации. Она может и должна быть конкретизирована с учетом региональных особенностей. 
«Двумерный» характер функций системы образования

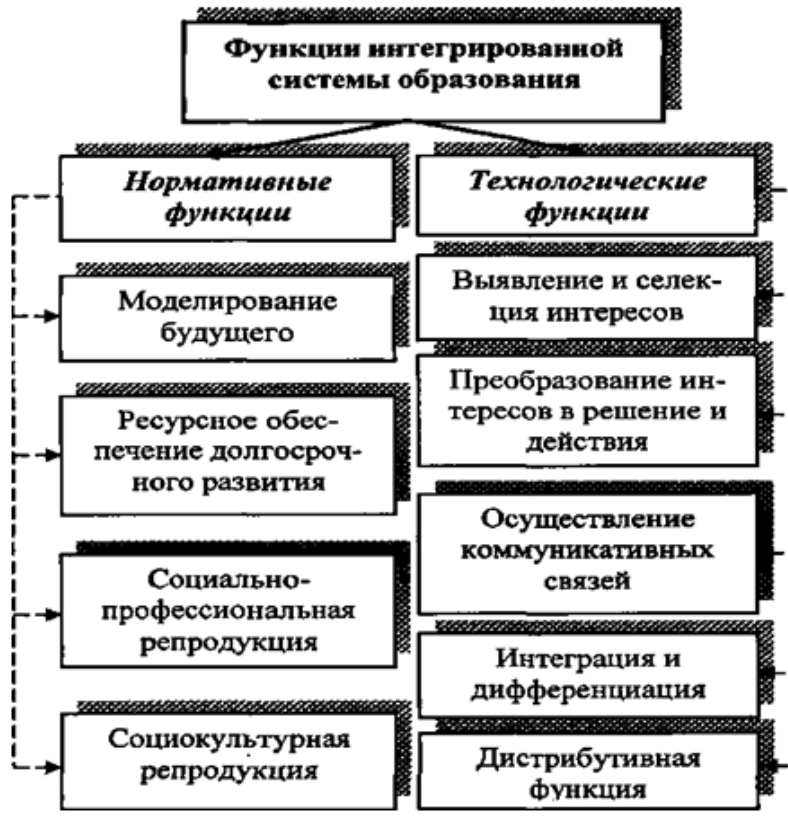

Департамент образования

\begin{tabular}{|c|}
\hline$\downarrow \downarrow$ \\
\hline Аналитнческнй отдел \\
\hline Отдел развития образования \\
\hline $\begin{array}{c}\text { Организационно-контрольное } \\
\text { управление }\end{array}$ \\
\hline Отдел воспитательных программ \\
\hline $\begin{array}{c}\text { Информачионно-сочиологический } \\
\text { отдел }\end{array}$ \\
\hline $\begin{array}{l}\text { Отдел организационно- } \\
\text { педагогической работы }\end{array}$ \\
\hline $\begin{array}{c}\text { Упраелениеразработки и реализации } \\
\text { интеграционных проектов }\end{array}$ \\
\hline
\end{tabular}

\section{3. Следуюшим и необходимым этапом является формирование системы управления региональным образовательным округом.}

Главной особенностью регионального учебного (образовательного) округа является то, что он формируется как добровольное объединение субъектов образовательной деятельности в регионе, а система управления данным округом строится на основе интеграции государственных структур и институтов гражданского общества. В основу деятельности всех организационных структур округа закладывается идея самоуправления. При этом возможны различные модели институционализации округа, которые в принципе аналогичны моделям университетских комплексов [9,22].

Главное, что создание университетского образовательного округа (в том числе с правом юридического лица), в котором университет играет роль центра методического обеспечения образовательных учреждений различных уровней, повышения квалификации преподавателей, формирует развитую информационную среду и ведет подготовку кадров для региона.

Этот вариант может рассматриваться как перспективное направление на будущее.

Институционализация образовательного округа предполагает, прежде всего, создание необходимой нормативно-правовой основы. Для этого необходимо: внесение соответствующих изменений в региональный закон об образовании, а при его отсутствии - разработку и принятие такого закона с положениями, регламентирующими статус образовательного округа; принятие следующих нормативных документов: учредительного договора о создании округа; устава округа; договора о совместной деятельности организаций и учреждений, входящих в состав округа; положения об образовательном округе. Создание структуры управления региональным округом, которая должна быть оптимизирована с существующей подсистемой управления образованием в регионе.

В управлении образованием в этом случае принимает участие мак-симальное количество факторов образовательного пространства, включая негосударственные общественные формирования и другие социальные институты. Несмотря на возможное разнообразие организационных форм, обозначенные выше общие организации учебных округов, очевидно, будут оставаться довольно стабильными. В результате процесс институционализации интеграционным развитием регионального института образования с созданием образовательного округа будет находить свое логическое воплощение и завершение. Однако институционализация управления может быть эффективной при условии дополнения ее мерами экономического и информационно-аналитического характера. 


\section{ЛИТЕРАТУРА}

1. Гальченко Н.А. Интегративные процессы как фактор повышения качества общего образования средней школы. Дис. . . кан. пед. наук. М., 2013.- С.151

2. Довжко Ф.Е. Общественно-государственный принцип управления системой НПО // Инновации в российском образовании. Начальное профессиональное образование. - М., 2000. - С. 3-14.

3. Игнатов В.Г. Становление государственного и муниципального управления. - Ростов-на/ Дону, 1998.-С. 61.

4. Лунев А.П. Совершенствование государственного управления системой высшего образования в регионе: Дис...д-ра экон. наук. - М., 2000. - С. 123-130.

5. Макаркин Н.П., Ивлев В.И. Региональный учебный округ в истории развития университетских комплексов // Интеграция образования. - 2001. - № 4. C. 11.

6. Нормативно-правовая основа деятельности системы образования Пермской области - http://www.perm.ru/educat/2001/law_edu.htm

7. Положение о департаменте образования администрации Владимирской области. Режим доступа: http://www.vpti.vladimir.ru/rus/educat/official/g_man. $\mathrm{htm}$; http://www.edu.murmansk.ru/www/komitet/about/functional.htm

8. Соловьев 0.В. Регулирование кадровых процессов в региональных органах государственной и муниципальной власти: Дис... канд. социол. наук. - Белгород, 2002.

9. Тучков М.Ф. Правовое регулирование образовательной деятельности. — 0рел, 2002. - С. 43.

10. Чурекова Т.М. Университетский образовательный округ: аспекты управления и взаимодействия // Интеграция образования. - 2003. - №3. - С.21-26.

(с Гальченко Наталья Александровна (galchenko.n.a@mail.ru).

Журнал «Современная наука: актуальные проблемы теории и практики»

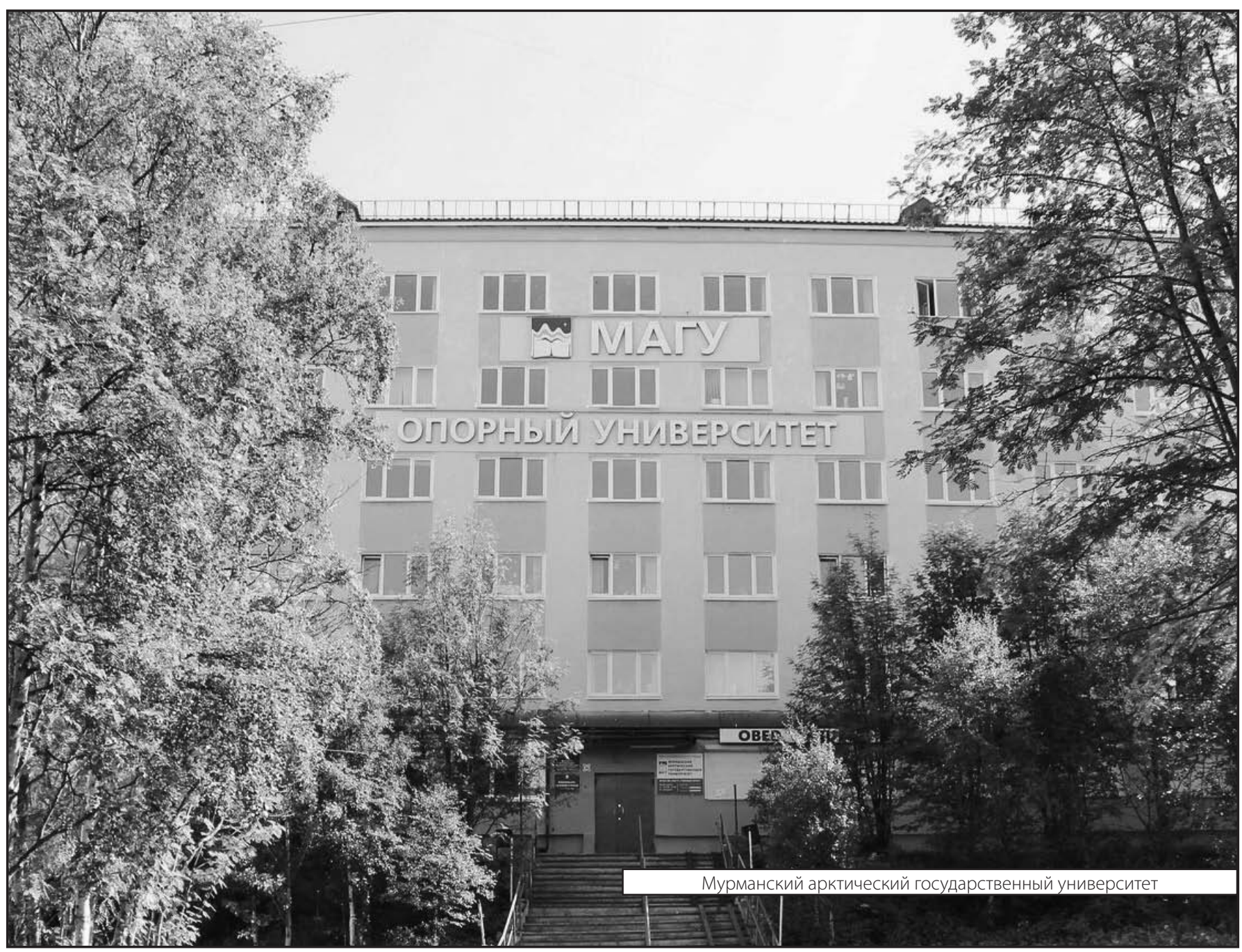

